\title{
Evaluation of Selected Renal Markers in Prostate Cancer
}

\section{*OLUBOYO, AO; ADELEKE, AT; OLUBOYO, BO}

\author{
Department of Medical Laboratory Science, College of Medicine and Health Sciences, Afe Babalola University, Ado Ekiti, Ekiti State, \\ Nigeria. \\ *Corresponding author: Email: oluboyoao@abuad.edu.ng:Tel: +2348062549343
}

\begin{abstract}
Prostate cancer is the most commonly diagnosed cancer in men and the second leading cause of cancer mortality. The study aimed to assess the level of urea, creatinine and cystatin $\mathrm{C}$ in prostate cancer subjects. The subjects consisted of 92 adult males between the ages of 45 to 70 years; 46 prostate cancer subjects and 46 apparently healthy subjects recruited from a Teaching Hospital in Nigeria. Urea and creatinine were estimated by colorimetric method, cystatin $\mathrm{C}$ was estimated using Enzyme linked immunosorbent assay (ELISA) technique. The results obtained showed that urea and creatinine were significantly high $(\mathrm{p}<0.05)$ while cystatin $\mathrm{C}$ was significantly low $(\mathrm{p}<0.05)$ in prostate cancer subjects compared with control subjects. Cystatin $\mathrm{C}$ was significantly high $(\mathrm{p}<0.05)$ in prostate cancer subjects on treatment compared with subjects not on treatment but there was no significant difference $(p>0.05)$ in the levels of urea and creatinine. The research concluded that increased serum urea and creatinine concentrations as well as decreased cystatin $\mathrm{C}$ level may pose higher risk of renal dysfunction in prostate cancer subjects. Thus, the levels of serum urea, creatinine and cystatin $\mathrm{C}$ need to be evaluated in prostate cancer subjects.
\end{abstract}

\section{DOI: https://dx.doi.org/10.4314/jasem.v23i9.18}

Copyright: Copyright (C) 2019 Oluboyo et al. This is an open access article distributed under the Creative Commons Attribution License (CCL), which permits unrestricted use, distribution, and reproduction in any medium, provided the original work is properly cited.

Dates: Received: 29 August 2019; Revised: 25 September 2019; 27 September 2019

Keywords: Prostate cancer, cystatin C, urea, creatinine

Prostate cancer (PC), an adenocarcinoma of the male prostate gland, has increasingly become an important health burden among men in the world (Ferlay et al., 2011; Lozano et al., 2012). Prostate cancer is the fourth most common cancer in both sexes combined and the second most common cancer in men. Infection or inflammation of the prostate (prostatitis) may increase the chance for prostate cancer especially infection with the sexually transmitted infections such as chlamydia, gonorrhea, or syphilis (Dennis et al., 2002). Whilst the primary risk factors include age and family history, other factors associated with cancer include hormonal imbalances, the living and working environment, lifestyle and diet, sexually transmitted infections, and exposure to certain medications (Grove et al., 2002). Over time, cancer cells begin to multiply and spread to the surrounding prostate tissue (the stroma) forming a tumor (Webber et al., 2016). Eventually, the tumor may grow large enough to invade nearby organs such as the seminal vesicles or the rectum, kidney or the tumor cells may develop the ability to travel in the bloodstream and lymphatic system. Prostate cancer is considered a malignant tumor because it is a mass of cells that can invade other areas of the body (Chen et al., 2017).

Cystatin C, a low molecular weight substance is removed from the bloodstream by glomerular filtration in the kidneys. It is expressed in all nucleated cells, widely distributed in human biological fluids, freely filtered through renal glomeruli, and uniquely and almost completely reabsorbed and catabolized in the proximal tubules (Ferguson and Waikar, 2012; Mori et al., 2016). Its classic role as a sensitive marker for renal function has been extensively studied (Yang et al., 2017). Urea is another renal marker but could be affected by a lot of factors that affects its suitability. It has been shown that by the action of urea transporter 2 , some urea is reabsorbed which eventually flows back into the thin descending limb of the tubule, through the collecting ducts, and into the excreted urine (Sands et al., 2011) thus making it one example of renal markers. Serum creatinine also is used in the detection and assessment of acute kidney injury and chronic kidney disease (Baumgarten, 2011).

It is a by-product of energy metabolism that is filtered from the blood by kidneys and is excreted into the urine (Tynkevich et al., 2014). The markers (urea, creatinine and cystatin C) were selected because they are readily filtered by the kidney and could easily be measured to assess kidney function. Therefore, there is need to evaluate the levels of these markers which will be of immense importance in the diagnosis of kidney dysfunction in prostate cancer. 


\section{MATERIALS AND METHODS}

Study Area and Subjects: The study area is Federal Medical Centre Ido Ekiti and its immediate environments, Ido-Ekiti. Ethical approval was sought for and obtained from Federal Medical Centre IdoEkiti. The nature and purpose of research was explained to each participant using an informed consent. A total of 92 serum samples were collected from male subjects within 40-70 years. Patients with acute urinary tract infection, smokers, alcoholics, diabetics and kidney disorders were excluded. The samples consisted of 46 cases of prostate cancer subjects and 46 healthy subjects as control. The prostate cancer subjects were further grouped into prostate cancer subjects on therapy and not on therapy. There were 19 cases of prostate cancer subjects on therapy (Androgen receptor inhibitor and alpha tocopherol supplement) and 27 cases of prostate cancer subjects not on therapy. Venous blood $(5 \mathrm{ml})$ was collected, separated and the serum was used for analysis of serum urea, creatinine and cystatin $\mathrm{C}$.

Methods of Analysis: Determination of serum urea using Urease-Berthelot colorimetric method (Taylor and Vadgama, 1992).

Principle: Urea in serum is hydrolyzed to ammonia in the presence of urease. The ammonia produced reacts with hypochlorite to form a blue coloured product which is directly proportional to the amount of urea present in the sample.

Determination of serum creatinine by Jaffe's Method (Spencer, 1996).

Principle: Creatinine in alkaline solution reacts with picric acid to form a colored complex. The amount of the complex formed is directly proportional to the creatinine concentration.

Determination of Cystatin C using ELISA kit purchased from Melsin, China (Jones et al., 2017)

Principle: The ELISA strip plate provided in the kit has been coated with purified cystatin $\mathrm{C}$ antibody to make solid-phase antibody. Serum samples are added to the wells followed by cystatin $\mathrm{C}$ antibody labeled horse raddish peroxidase (HRP). After incubation and washing, the addition of chromogen solution changes the color to blue. At the effect of addition of acid, the colour finally becomes yellow.

This color change is measured spectrophotometrically at wavelength of $450 \mathrm{~nm}$. The concentration of cystatin
$\mathrm{C}$ in the samples is then determined by comparing the optical density of the samples to the standard curve.

Statistical analysis: The data obtained were subjected to statistical analysis using Statistical Package for Social Sciences version 23. All parameters were expressed as mean \pm standard deviation (SD) and results were presented on tables and chart. Student ttest was used to determine the level of significance at $\mathrm{p}<0.05$.

\section{RESULTS AND DISCUSSION}

In this research, cystatin $\mathrm{C}$ was significantly low in prostate cancer subjects compared with control. This supports the findings of Cox (2017) and Wang et al., (2018) where cystatin C was reported to be low in prostate cancer. The decreased level may be the reason for cancer progression since cystatin $\mathrm{C}$ is believed to play a key role in tumor suppression. Cystatin $\mathrm{C}$ is a useful marker because its concentration in body fluids does not depend on gender, age or muscle mass. It only depends on the glomerular filtration rate, which also makes it a good indicator of urinary tract function (Guo et al., 2018).

On the other hand, Cystatin $\mathrm{C}$ was significantly high in prostate cancer subjects on therapy compared with those not on therapy which may be attributed to the effects of the drugs being used by the subjects. The result in this research shows that urea is significantly increased in prostate cancer subjects when compared with the control which agrees with the work of Edmund et al., (2012) where increase in urea level had been reported. Urea has been used as a marker of renal function, though it is being regarded to be inferior to other markers such as creatinine because blood urea levels are influenced by other factors such as diet and dehydration (Traynor et al., 2006; Ikuerowo et al., 2013).

There was no significant difference when the urea level in prostate cancer subjects on therapy was compared with those not on therapy. Also, creatinine was significantly increased in prostate cancer subjects compared with the control which agrees with the works of Jemal et al., (2008) which reported higher level in creatinine but there was no significant difference when those on therapy were compared with subjects not on therapy.

Serum creatinine has been shown to be useful in the detection and assessment of acute kidney injury and chronic kidney disease (Baumgarten, 2011). 
TABLE 1: Urea, Creatinine and Cystatin $C$ in prostate cancer subjects and control

\begin{tabular}{|c|c|c|c|c|}
\hline Parameters & Prostate cancer subjects $(n=46)$ & Control $(n=46)$ & value & value \\
\hline Urea & $6.08 \pm 0.95$ & $5.06 \pm 0.90$ & 5.2530 & $0.000^{*}$ \\
\hline Creatinine & $91.80 \pm 15.19$ & $85.58 \pm 14.13$ & 2.0330 & $0.045^{*}$ \\
\hline Cystatin C & $65.21 \pm 12.25$ & $94.15 \pm 14.43$ & 10.3601 & $0.000^{*}$ \\
\hline
\end{tabular}

Table 2: Urea, Creatinine and Cystatin C in prostate cancer subjects on therapy and those not on therapy.

\begin{tabular}{lllll}
\hline Parameters & $\begin{array}{l}\text { On Therapy } \\
(\mathrm{n}=19)\end{array}$ & $\begin{array}{l}\text { Not on Therapy } \\
(\mathrm{n}=27)\end{array}$ & T value & P value \\
Urea & $5.93 \pm 1.14$ & $6.19 \pm 0.79$ & -0.9080 & 0.369 \\
Creatinine & $93.57 \pm 16.69$ & $90.55 \pm 14.24$ & 0.6421 & 0.525 \\
Cystatin C & $75.57 \pm 11.72$ & $57.92 \pm 5.57$ & 6.0981 & $0.000^{*}$ \\
\hline \multicolumn{5}{c}{ Key: $*$ significant at $p<0.05$}
\end{tabular}

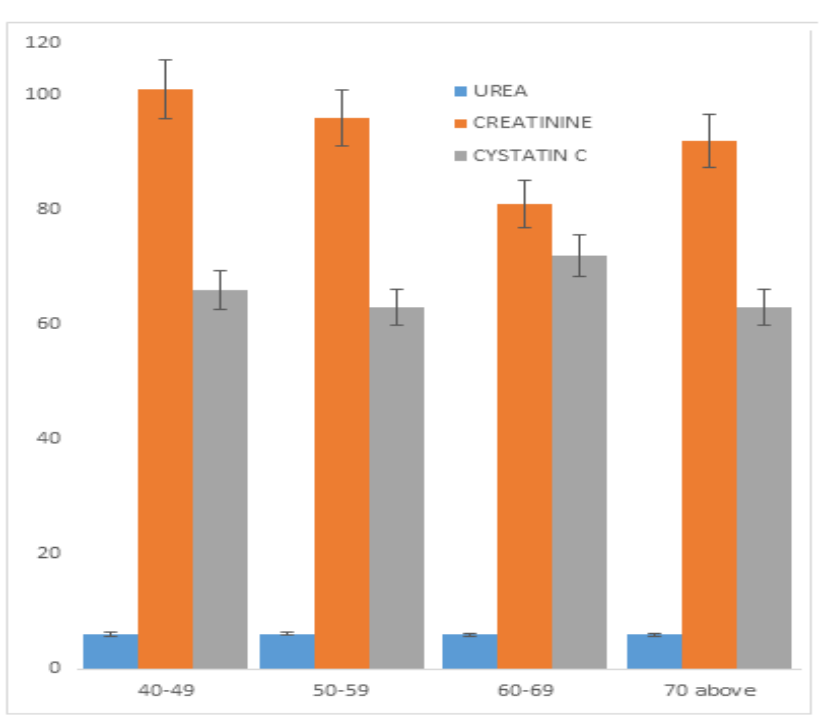

Fig 1: Urea, Creatinine and Cystatin $C$ relative to their age groups

There was significant difference in age when the age groups were compared in prostate cancer subjects. It has been shown that the risk of development of prostate cancer increases significantly after the age of 50 in white men who have no family history of the disease and after the age of 40 in black men and the men who have a close relative with prostate cancer. This is also in agreement with the report which stated that prostate cancer is uncommon in men younger than 40 years, but becomes more common with advancing age (Ngugi et $a l ., 2007)$. This study therefore showed that the levels of blood urea and creatinine were significantly high and cystatin $\mathrm{C}$ was significantly low in prostate cancer subjects compared with control. Cystatin C was significantly high in prostate cancer subjects on therapy compared with those not on therapy showing that the drugs had effects on the subjects.

Conclusively, increased serum urea and creatinine concentrations as well as decreased cystatin $\mathrm{C}$ may pose higher risk of renal dysfunction in prostate cancer subjects. Thus, the level of serum urea, creatinine and cystatin $\mathrm{C}$ levels need to be evaluated in prostate cancer subjects.
Acknowledgement: The Authors acknowledge the support of the staff members of Chemical Pathology Laboratory of Federal Medical Center, Ido Ekiti, Ekiti State for their support during sample collection.

\section{REFERENCES}

Baumgarten, M (2011). Chronic kidney disease: Detection and evaluation. Am. Fam. Physician. 84 (10):1138-1148.

Burtis, CA; Ashwood ER (1999). Tietz Textbook of Clinical Chemistry. 3rd ed. Philadelphia, WB Saunders: 729-731.

Chen, RC; Basak, R; Meyer, AM; Kuo TM; Carpenter WR; Agans RP; Broughman JR; Reeve BB; Nielsen ME; Usinger DS; Spearman KC; Walden S; Kaleel D; Anderson M; Stürmer T; Godley PA.(2017). Association between choice of radical prostatectomy, external beam radiotherapy, brachytherapy, or active surveillance and patientreported quality of life among men with localized prostate cancer. JAMA. 317(11):1141-1150. 
Cox, J (2017). Cystatins as regulators of cancer. Medical Research Archives. 5 (7). ISSN 2375-1924. Available at: https://journals.kei.org/index.php/mra/article/view/1252

Dennis, LK; Lynch, CF; Torner, JC (2002). Epidemiologic association between prostatitis and prostate cancer. Urology. 60 (1): 78-83.

Edmund, DC; Sanda, MG; Dunn, RL (2012). Long-term outcomes among localized prostate cancer survivors: health-related quality-of-life changes after radical prostatectomy, external radiation, and brachytherapy. J. Clin. Oncol. (12):2772-80.

Ferguson, MA; Waikar, SS (2012). Established and emerging markers of kidney function. Clin. Chem. 58 (4): 680-689

Ferlay, J; Shin, HR; Bray, F; Forman, D; Mathers, C; Parkin, DM (2011). Estimates of worldwide burden of cancer. Int. J. Cancer. 127(12), 2893-2917

Grove, JS; Severson, RK; Nomura, A; Stemmermann, GN (2002). Body mass and prostatic cancer: a prospective study. BMJ. 297:713-715.

Guo, K; Chen, Q; He, X; Yao, K; Li, Z; Liu, Z; Chen, J; Liu, Z; Guo, C; Lu, J; Wu, C; Li, W; Wang, Q; Chen, P; Lu, W; Wang, Y; Han, H; Cao, Y; Guo, S (2018). Expression and significance of Cystatin- $\mathrm{C}$ in clear renal cell carcinoma. Biomedicine and Pharmacotherapy. 107: 1237-1245.

Ikuerowo, SO; Omisanjo, OA; Bioku, MJ; Ajala, MO; Mordi, VPN; Esho JO (2013). Prevalence and characteristics of prostate cancer among participants of a community-based screening in Nigeria using serum prostate specific antigen and digital rectal examination. Pan. Afr. Med. J;15: 129.

Jemal, A; Siegel, R; Ward, E (2008). Cancer statistics. CA Cancer J. Clin. 58:71-96

Jones,M; Denieffe, S; Griffin, C; Tinago,W; Fitzgibbo, MC (2017). Evaluation of cystatin $C$ in malignancy and comparability of estimates of GFR in oncology patients. Pract. Lab. Med. 8: 95-104.

Lozano, R; Naghavi, M; Foreman, K; Lim, S; Shibuya, K; Aboyans, V (2012). Global and regional mortality from 235 causes of death for 20 age groups: a systematic analysis for the Global Burden of Disease Study. Lancet. 380 (9859), 2095-2128.
Mori, J; Tanikawa, C; Funauchi, Y; Lo, PHY; Nakamura, $\mathrm{Y}$; Matsuda, K (2016). Cystatin C as a p53inducible apoptotic mediator that regulates cathepsin L activity. Cancer Science. 107 (3) :298-306.

Ngugi, PM (2007) An update on the treatment of advanced prostate cancer. East. Afr. Med. J. 84: S36-S39

Sands, JM; Blount, MA; Klein, JD (2011). Regulation of Renal Urea Transport by Vasopressin. Trans. Am. Clin. Climatol. Assoc. 122: 82-92.

Spencer, K (1996). Analytical reviews in clinical biochemistry: The estimation of creatinine. Ann. Clin. Biochem. 23: 1-25.

Taylor, AJ; Vadgama, P (1992). Analytical reviews in clinical biochemistry: The estimation of urea. Ann. Clin. Biochem. 29: 245-264.

Traynor, J; Mactier, R; Geddes, CC (2006). How to measure renal function in clinical practice. $B M J$. 333(7571):733-737.

Tynkevich, E; Flamant, M; Haymann, JP; Metzger, M; Thervet, E; Boffa, JJ (2014). Decrease in urinary creatinine excretion in early stage chronic kidney disease. PLoS ONE. 9(11): e111949.

Wang H; Gao, L; Meng,C ;Yu,N; Yang,F; Zhang,C; Li D; Yan,L; Liu,H; Xu Z (2018). Serum cystatin C level is not a promising biomarker for predicting clinicopathological characteristics of bladder urothelial tumors. BioMed. Research International. Article ID 2617439, 8 pages. https://doi.org/10.1155/2018/2617439

Webber, JP; Spary, LK; Mason, MD; Tabi, Z; Brewis, IA; Clayton, A (2016). Prostate stromal cell proteomics analysis discriminates normal from tumour reactive stromal phenotypes. Oncotarget. 2; 7(15): 20124-20139.

Yang,F ; Li,D ; Di, Y ; Zhang, Y ; Zang,Y ; Ren, J ; Yan,L ; Zhou, Z ; Liu, H ; Xu, Z (2017). Pretreatment serum cystatin $\mathrm{C}$ levels predict renal function, but not tumor characteristics, in patients with prostate neoplasia. BioMed. Research International. https://doi.org/10.1155/2017/7450459

Zhang, X; Zhou, W; Chen, Z; Hu, W; Shen, M; Li, C (2016). Association of short tandem repeat polymorphism in the promoter of prostate cancer antigen 3 gene with the risk of prostate cancer. PLoS One. 6(5), e20378. 